\title{
Evaluation of Emotional Blunting in Behavioral Variant Frontotemporal Dementia Compared to Alzheimer's Disease
}

\author{
Aditi Joshi ${ }^{a, c}$ Joseph P. Barsuglia ${ }^{c}$ Michelle J. Mather ${ }^{a, c}$ \\ Elvira E. Jimenez ${ }^{a, c}$ Jill Shapira ${ }^{a-c}$ Mario F. Mendez ${ }^{a-c}$ \\ Departments of a Neurology, ${ }^{b}$ Psychiatry and Biobehavioral Sciences, David Geffen School \\ of Medicine, University of California, and 'VA Greater Los Angeles Healthcare System, \\ Los Angeles, Calif., USA
}

\author{
Key Words \\ Scale for Emotional Blunting · Dementia · Caregiver
}

\begin{abstract}
Background: Emotional blunting is a major clinical feature of behavioral variant frontotemporal dementia (bvFTD). Assessing the change in emotional blunting may facilitate the differential diagnosis of this disorder and can quantify a major source of distress for the patients' caregivers and families. Methods: We evaluated investigator ratings on the Scale for Emotional Blunting (SEB) for 13 patients with bvFTD versus 18 patients with early-onset Alzheimer's disease (AD). The caregivers also performed SEB ratings for both the patients' premorbid behavior (before dementia onset) and the patients' behavior on clinical presentation (after dementia onset). Results: Before the onset of dementia, the caregivers reported normal SEB scores for both dementia groups. After the onset of dementia, both caregivers and investigators reported greater SEB scores for the bvFTD patients compared to the AD patients. The patients were rated to be much more emotionally blunted by the bVFTD caregivers than by the investigators. A change of $\geq 15$ in the caregiver SEB ratings suggests bvFTD. The change in caregiver SEB ratings was positively correlated with bifrontal hypometabolism on FDG-PET scans. Conclusions: Changes in the caregiver assessment of emotional blunting with dementia onset can distinguish patients with bvFTD from those with $A D$, and they may better reflect the impact of emotional blunting than similar assessments made by clinicians/investigators.
\end{abstract}




\begin{tabular}{l|l}
\hline \multicolumn{2}{|l}{ Dement Geriatr Cogn Disord 2014;38:79-88 } \\
\hline DOI: $\underline{10.1159 / 000357838}$ & $\begin{array}{l}\text { C 2014 S. Karger AG, Basel } \\
\text { www.karger.com/dem }\end{array}$ \\
\hline
\end{tabular}

Joshi et al.: Evaluation of Emotional Blunting in Behavioral Variant Frontotemporal Dementia Compared to Alzheimer's Disease

\section{Introduction}

Emotional blunting is a major aspect of behavioral variant frontotemporal dementia (bvFTD) and underlies symptoms such as apathy and lack of empathy [1]. bvFTD is a neurodegenerative disease characterized by behavioral disinhibition, apathy, lack of empathy, compulsive behaviors, changes in eating behavior, and a dysexecutive neuropsychological profile [2]. Investigators have described emotional blunting in bvFTD as inappropriate emotional shallowness with unconcern and loss of emotional warmth, empathy, and sympathy, and an indifference to others' [3]. This symptom also contributes to the interpersonal disengagement and decreased social tact observed in these patients [4]. On neuropathology, emotional blunting may result from frontolimbic involvement $[5,6]$ and may be particularly associated with tau-positive neuropathological findings in bvFTD [7, 8]. In 2003, Boone et al. [9] identified emotional blunting as a negative symptom of dementia that differentiated individuals with FTD from those with Alzheimer's disease (AD).

Although the presence of emotional blunting is helpful in the differential diagnosis of bvFTD patients $[1,10]$, its clinical assessment poses several challenges. The construct is difficult to define and to accurately assess [2]. First, there are intra-individual differences in emotional blunting. Clinicians must consider differences in culture, degree of interpersonal affiliation, social milieu, and presumed premorbid functioning in determining what constitutes pathologic expression of affect $[11,12]$. Second, the accurate appraisal of emotional warmth or empathy requires a degree of relatedness that may be difficult for a clinician to witness in an initial or brief medical evaluation. For these two reasons, assessment by a close caregiver-informant may offer a more accurate appraisal of emotional blunting in patients, compared to clinician impressions alone $[13,14]$. In general, caregiver-based questionnaires of behavioral changes among patients with bvFTD have yielded relatively high sensitivities and specificities for discriminating bvFTD patients from those with $\operatorname{AD}[15,16]$. Finally, this study differs in not just evaluating emotional blunting at one point in time, which is subject to individual differences in baseline emotional reactivity and expression, but in evaluating the individual's change in emotional blunting with the development of dementia.

In the present study, the primary goal was to compare bvFTD patients with AD patients considering changes in emotional blunting. This study examined caregiver-informant ratings of emotional blunting before and after dementia onset in a group of patients with bvFTD, compared to age-matched patients with AD. Furthermore, we compared these caregiver ratings with those performed by a neuropsychologist after dementia onset. We predict larger changes in emotional blunting among the bvFTD patients compared to the AD patients and that, given the greater personal relatedness, caregivers will report greater emotional blunting than the researchers.

\section{Methods}

\section{Participants}

On approval from the Institutional Review Boards of the University of California, Los Angeles, and the Veterans Administration Healthcare Center, Greater Los Angeles, participants were recruited from the UCLA Behavioral Neurology Program and Clinic. The participants were community-based, mild-to-moderately impaired dementia patients who underwent a clinical neurobehavioral evaluation. Patients unable to respond to basic neuropsychological testing or presenting with evidence of cortical infarction, and other cortical or significant subcortical lesion on MRI of the brain, i.e., all subcortical lesions except for mild white matter capping of the lateral ventricles (based on Fazekas scale lesion stages 1-3 [17]) were excluded. In addition, for each participant the study enrolled a caregiver-informant who lived with the patient or interacted in person with the patient several times each week. 
Joshi et al.: Evaluation of Emotional Blunting in Behavioral Variant Frontotemporal Dementia Compared to Alzheimer's Disease

Table 1. Patient vs. caregiver characteristics for the bvFTD vs. early-onset AD groups

\begin{tabular}{|c|c|c|c|c|}
\hline & bvFTD (n = 13) & $\mathrm{AD}(\mathrm{n}=18)$ & Significance & $\mathrm{p}$ \\
\hline \multicolumn{5}{|l|}{ Patient } \\
\hline Age, years & $60.29(11.22)$ & $58.56(4.56)$ & n.s. & \\
\hline Male gender, $\mathrm{n}$ & $7(53.8 \%)$ & $7(38.8 \%)$ & n.s. & \\
\hline MMSE score & $22.92(3.50)$ & $24.18(3.94)$ & n.s. & \\
\hline White ethnicity, n & $11(84.6 \%)$ & $17(94.4 \%)$ & n.s. & \\
\hline Education, years & $15.15(2.47)$ & $15.94(2.23)$ & n.s. & \\
\hline Disease duration, years & $3.38(1.26)$ & $3.94(2.23)$ & n.s. & \\
\hline TMT Part A, s & $65.36(50.91)$ & $66.82(59.26)$ & $t(22)=-0.06$ & 0.95 \\
\hline TMT Part B, s & $236.46(96.29)$ & 194.44 (94.59) & $\mathrm{t}(20)=0.98$ & 0.34 \\
\hline Digits forward (span length) & $8.27(2.28)$ & $7.82(2.78)$ & $t(20)=0.42$ & 0.68 \\
\hline Digits backward (span length) & $3.18(2.31)$ & $3.73(2.20)$ & $\mathrm{t}(20)=-0.57$ & 0.58 \\
\hline \multicolumn{5}{|l|}{ Caregiver } \\
\hline Age, years & $58.91(15.7)$ & $62.75(11.3)$ & n.s. & \\
\hline Male gender, $\mathrm{n}$ & 4 & 9 & n.s. & \\
\hline ZBI-22 total score & $45.0(19.1)$ & $26.9(16.6)$ & $t(29)=2.8$ & 0.008 \\
\hline Relationship (spouse), n & $12(92.3 \%)$ & $15(83.3 \%)$ & n.s. & \\
\hline Cohabiting with patient, $\mathrm{n}$ & $11(84.6 \%)$ & $17(94.4 \%)$ & n.s. & \\
\hline
\end{tabular}

Values in parentheses are SD or percentages. Data was missing in 1 patient with bvFTD and in 1 patient with $\mathrm{AD}$.

The bvFTD participants $(n=13)$ in this study presented with progressive behavioral changes including declines in social interpersonal conduct, impairment in the regulation of personal conduct, emotional blunting, and loss of insight into their disease, and they met criteria for 'probable bvFTD' based on the International Consensus Criteria for bvFTD [2]. The clinical diagnosis of probable bvFTD was confirmed by the presence of predominant frontal and anterior temporal hypometabolism on fluorodeoxyglucose positron emission tomography (FDG-PET) neuroimaging.

The comparison group consisted of 18 patients with early-onset AD (age of onset <65 years). These patients met the National Institute of Neurological and Communicative Disorders and Stroke and the Alzheimer's Disease and Related Disorders Association (NINCDS-ADRDA) criteria for clinically probable AD after completing a diagnostic evaluation [18]. The AD group was matched to the bvFTD patients according to demographic factors relevant to the dementia course including age, gender, years of education, and ethnicity. The groups were not significantly different on clinical characteristics including disease duration, gross cognition on the Mini-Mental State Examination (MMSE), and neuropsychological measures of executive functioning (table 1).

\section{Measures}

The Scale for Emotional Blunting (SEB) $[1,19]$, which was initially developed to characterize negative symptoms in schizophrenia $[19,20]$, has proven to be an effective instrument in assessing the presence of blunting in bvFTD $[1,9]$. The SEB takes approximately 15-30 min. Each behavioral symptom is scored on a 3 -point scale where 0 is 'condition absent', 1 is 'slightly present or doubtful', and 2 is 'clearly present'. Items are summed up into three domains: absence of pleasure-seeking behavior (Behavior), affective blunting (Affect), and cognitive blunting (Thought). The behavior subscale has seven items (e.g. 'reclusive, avoids social contact'), whereas the affect subscale has four items (e.g. lacks warmth, empathy). The thought subscale has five items (e.g. lacks plans, ambition, desires, drive). In the initial validation sample, interrater reliability was 0.83 , with a reliability coefficient of 0.77 (Kendall's coefficient of concordance) $(p<0.01)$ [19].

Demographic differences are provided for the MMSE [21] and on the Neuropsychiatric Inventory (NPI-Q) [22]. Caregiver burden was assessed with the Zarit Burden Interview (ZBI-22) [23], and caregivers also provided information on the Functional Activities Questionnaire (FAQ) for the patients. Group differences were presented on cognitive measures of executive functioning including the Trail Making Test (TMT), 
Joshi et al.: Evaluation of Emotional Blunting in Behavioral Variant Frontotemporal

Dementia Compared to Alzheimer's Disease

Parts A and B [24], and a digit span task (maximum span forward and backward). For the bvFTD patients, clinical PET scan reports from a variety of scanners were rated for regional hypometabolism as absent, mild, moderate, or severely present (0- to 3-point scale) for each of the left frontal, right frontal, left anterior temporal, and right anterior temporal regions.

\section{Procedure}

Data regarding emotional blunting was collected during one of three on-site research visits. The SEB was completed by the neuropsychologist subsequent to a neuropsychological testing session. The neuropsychologist engaged in a rapport-building conversation and observed patients' verbal and nonverbal responses to the testing environment. This interview was designed to elicit emotional responses on the 16 items of the SEB and was in accordance with the original SEB administration guidelines [19]. The caregivers completed an identical version of the SEB as the rater. The SEB was completed twice by the caregivers for two different time points: (1) before the onset of dementia symptoms (before onset), and (2) for present-day functioning (after onset). The scale items were identical to the scale completed by the neuropsychologist. It was administered aurally to the caregiver by a research assistant, and the patient was not present during data collection. Clarification of terminology was provided if requested.

\section{Statistical Analysis}

Data analysis was conducted using SPSS version 20 (IBM Inc.). Independent sample t tests were computed to assess group differences on demographics (patient and caregiver), FAQ and the NPI. The $\chi^{2}$ test was performed to assess group differences on categorical variables as appropriate. Repeated-measures ANOVA compared group differences before dementia onset and after dementia onset on SEB caregiver ratings. Repeated-measures ANOVA also compared group differences between caregiver and researcher SEB ratings after dementia onset.

We computed a difference score after dementia onset and before dementia onset for caregiver SEB ratings. An independent sample t test assessed the difference score between diagnostic groups. Separate ANCOVAs examined the contribution of caregiver burden and the FAQ score on the caregiver SEB rating difference scores. A binary logistic regression model investigated the difference score before and after dementia onset as a predictor of the dementia diagnosis. Further analysis by the receiver operator characteristics (ROC) curve determined the optimal cutoff scores. A correlation analysis evaluated the association between regional hypometabolism indicated on PET scans and caregiver SEB difference scores. HolmBonferroni correction was applied for correction of multiple comparisons.

\section{Results}

\section{Demographics}

No significant differences were observed for age, gender, education, or ethnicity of the participants across the two groups. Participants also did not differ in age of disease onset, disease duration, gross cognition (MMSE), or executive functioning (TMT, digit span task) (table 1). No significant differences were observed in the age or gender of the caregivers. The caregivers were primarily spouses $(n=27)$. Nonspouse caregivers $(n=4)$ included two parents, one sibling, and one child of the patient. No significant difference was observed in cohabitation of caregivers with patients across the two groups: 2 bvFTD patients and 1 AD patient did not live with the caregiver. However, the caregivers of the bvFTD group reported significantly higher caregiver burden on the ZBI-22 as compared to the caregivers of the AD group ( $\mathrm{p}<0.05)$ (table 1$)$.

On the FAQ, the bvFTD caregivers reported more impairment in functional activities of their patient, as compared to the AD group ( $p=0.002)$. On the NPI, the bvFTD caregivers reported greater presence of apathy, elation, disinhibition, aberrant motor behavior and eating symptoms than the AD caregivers $(p<0.05)$. In contrast, the AD caregivers reported greater presence of depression in their patients as compared to bvFTD caregivers $(p<0.05)$ (table 2). 
Joshi et al.: Evaluation of Emotional Blunting in Behavioral Variant Frontotemporal Dementia Compared to Alzheimer's Disease

Table 2. Neuropsychological characteristics of the patients based on the NPI-Q $(n=13)$

\begin{tabular}{|c|c|c|c|c|}
\hline & bvFTD & $\mathrm{AD}(\mathrm{n}=18)$ & Significance & $\mathrm{p}$ \\
\hline NPI Apathy & $12(92.3 \%)$ & $8(44.4 \%)$ & $\chi^{2}=7.5$ & 0.006 \\
\hline NPI Delusions & $2(15.3 \%)$ & $2(11.1 \%)$ & n.s. & \\
\hline NPI Hallucination & $2(15.3 \%)$ & 0 & n.s. & \\
\hline NPI Agitation & $7(53.8 \%)$ & $4(22.2 \%)$ & n.s. & \\
\hline NPI Depression & $2(15.3 \%)$ & $9(50 \%)$ & $\chi^{2}=3.9$ & 0.04 \\
\hline NPI Anxiety & $3(23.0 \%)$ & $9(50 \%)$ & n.s. & \\
\hline NPI Elation & $6(46.1 \%)$ & 0 & $\chi^{2}=9.8$ & 0.002 \\
\hline NPI Disinhibition & $12(92.3 \%)$ & $3(16.6 \%)$ & $\chi^{2}=17.2$ & 0.00 \\
\hline NPI Irritation & $5(38.4 \%)$ & $7(38.8 \%)$ & n.s. & \\
\hline NPI Aberrant Motor Behavior & $13(100 \%)$ & $5(27.7 \%)$ & $\chi^{2}=16.1$ & 0.00 \\
\hline NPI Nighttime Behavior & $4(30.7 \%)$ & $5(27.7 \%)$ & n.s. & \\
\hline NPI Eating Behavior & $13(100 \%)$ & $3(16.6 \%)$ & $\chi^{2}=20.9$ & 0.00 \\
\hline FAQ & $19.0(5.1)$ & $12.0(6.0)$ & $t(29)=3.3$ & 0.002 \\
\hline
\end{tabular}

Table 3. Before dementia and after dementia scores of the caregiver-informant ratings on the SEB

\begin{tabular}{lllllll}
\hline $\begin{array}{l}\text { SEB } \\
\text { caregiver }\end{array}$ & $\begin{array}{l}\text { bvFTD before } \\
(\mathrm{n}=13)\end{array}$ & $\begin{array}{l}\text { bvFTD after } \\
(\mathrm{n}=13)\end{array}$ & Diff. score & $\begin{array}{l}\text { AD before } \\
(\mathrm{n}=18)\end{array}$ & $\begin{array}{l}\text { AD after } \\
(\mathrm{n}=18)\end{array}$ & Diff. score \\
\hline Total & $2.31(1.8)$ & $23.0(7.9)$ & $20.7(6.8)$ & $2.61(4.3)$ & $6.67(6.0)$ & $4.6(5.8)$ \\
Affect & $0.62(1.0)$ & $6.23(2.7)$ & $5.6(2.7)$ & $1.11(1.9)$ & $2.00(2.2)$ & $0.8(1.7)$ \\
Behavior & $1.46(1.3)$ & $10.08(4.1)$ & $8.6(3.4)$ & $1.11(1.8)$ & $3.17(3.13)$ & $2.0(2.9)$ \\
Thought & $0.23(0.4)$ & $6.77(1.7)$ & $6.5(1.6)$ & $0.39(0.6)$ & $1.50(1.79)$ & $1.1(1.9)$ \\
\hline
\end{tabular}

Values in parentheses are SD.

\section{Caregiver SEB Analysis}

Repeated-measures ANOVA to assess the effect of diagnosis in the groups (FTD or AD) on caregiver ratings of total SEB score (before dementia onset vs. after dementia onset) showed a significant group-diagnosis interaction $[F(1,29)=52.93, p=0.001]$. No significant group differences were observed in the caregiver rating at the time point before dementia onset, but the bvFTD caregivers reported higher total SEB scores than the AD caregivers after dementia onset when compared to before the onset of dementia $(p<0.001)$ (table 3). There were similar results of separate repeated-measures ANOVAs for each after-onset subscale score. The caregivers of the bvFTD group reported greater emotional blunting on subscales measuring affect $[\mathrm{F}(1,29)=35.21, \mathrm{p}=0.001]$, behavior $[\mathrm{F}(1,29)=32.7, \mathrm{p}=0.001]$ and thought content $[F(1,29)=67.8, p=0.001]$ (table 3).

We calculated an SEB difference score by subtracting caregiver SEB ratings before dementia onset from those after dementia onset. A binary logistic regression model examined caregivers' SEB difference scores as a predictor of the diagnostic group (bvFTD vs. AD). The caregivers' SEB difference scores were a significant predictor of the diagnostic group $\left(\chi^{2}=\right.$ $24.39, \mathrm{p}=<0.001$, d.f. $=1$ ) (table 4 ) and correctly classified $90.3 \%$ of the sample (11 of 13 bvFTD and 17 of 18 AD). ANCOVA showed that the degree of caregiver burden (ZBI-22) did not predict the caregivers' SEB difference score $[F(1,28)=1.7, p=0.19]$.

ROC analysis was performed in order to obtain optimal cutoff scores. The study plotted the ROC curve [sensitivities vs. false positives (1 - specificity)] for the caregivers' SEB difference scores and identified potential cutoff scores for distinguishing bvFTD patients 
Dementia

Fig. 1. ROC curve analysis for the caregiver SEB difference score. A plot with different cutoff scores is presented.

Table 4. Binary logistic regression model analyzing caregiver SEB difference score as a predictor of the diagnostic group in bvFTD $(\mathrm{n}=11)$ and $\mathrm{AD}(\mathrm{n}=17)$

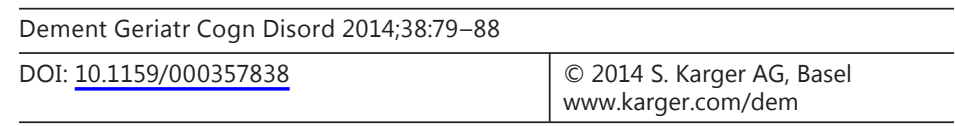

Joshi et al.: Evaluation of Emotional Blunting in Behavioral Variant Frontotemporal Dementia Compared to Alzheimer's Disease

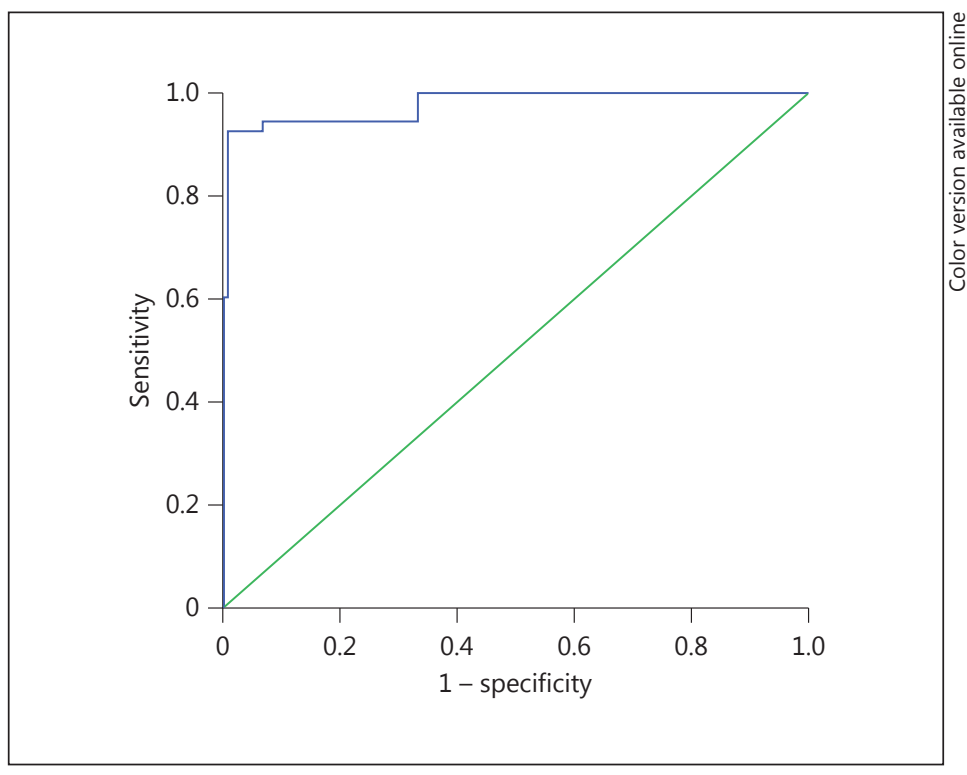

\begin{tabular}{|c|c|c|c|c|c|c|}
\hline & B & SE & $\begin{array}{l}\text { Wald's } \\
\chi^{2}\end{array}$ & d.f. & $\mathrm{p}$ & OR \\
\hline Constant & 3.42 & 1.15 & 8.84 & 1 & 0.003 & 30.62 \\
\hline $\begin{array}{l}\text { SEB diff. score } \\
\text { Test }\end{array}$ & -0.26 & 0.08 & $\begin{array}{l}10.41 \\
\chi^{2}\end{array}$ & 1 & 0.001 & 0.77 \\
\hline Overall model & & & 24.39 & 1 & 0.000 & \\
\hline
\end{tabular}

Overall model: $\mathrm{R}^{2}=0.54$ (by Cox and Snell test), 0.73 (by Nagelkerke), $-2 \log$ likelihood $=17.78$.

from AD patients (AUC $=0.978, p<0.001$ ) (fig. 1). The SEB difference had an optimal cutoff of $\geq 15$ with a sensitivity of $92 \%$ and a specificity of $80 \%$ for bvFTD compared to AD. The positive predictive value was $84.6 \%$ and the negative predictive value was $94.4 \%$. In this small series, 2 bvFTD patients and 1 AD patient would have been misclassified based on the SEB difference score. In comparison, researchers rated 6 of the FTD patients as mild on the SEB $(<12,12$ is the optimal cutoff for the researcher SEB), hence resulting in a higher percentage of misclassifications.

\section{Correlation Analysis}

The relationship between caregiver SEB ratings after dementia onset and the ZBI-22 scores was examined by a correlation analysis. The ZBI-22 total score had a positive correlation with the caregiver SEB total score $[\mathrm{r}(31)=0.467, \mathrm{p}=0.008]$ as well as the Affect $[\mathrm{r}(31)=0.461, \mathrm{p}=$ 0.009], Behavior $[r(31)=0.380, p=0.035]$, and Thought content $[r(31)=0.510, p=0.003]$ subscores. Another correlation analysis further validated the association between caregiver SEB ratings after dementia onset and the NPI items. There was a significantly positive correlation between caregiver SEB ratings after dementia onset and Elation $[\mathrm{r}(30)=0.546, \mathrm{p}=0.002]$, Apathy $[r(31)=0.694, p<0.01]$, Disinhibition $[r(31)=0.632, p<0.01]$, Aberrant Motor Behavior $[r(31)=0.605, p<0.01]$, and Eating Behaviors $[r(31)=0.666, p<0.01]$. 
Dementia

Cognitive Disorders

Fig. 2. Comparison of SEB scores (after onset of dementia) reported by the observers.

Table 5. Researcher and caregiver mean SEB scores after disease onset

\begin{tabular}{l|l}
\hline Dement Geriatr Cogn Disord 2014;38:79-88 \\
\hline DOI: $\underline{10.1159 / 000357838}$ & $\begin{array}{l}\text { @ 2014 S. Karger AG, Basel } \\
\text { www.karger.com/dem }\end{array}$ \\
\hline
\end{tabular}

Joshi et al.: Evaluation of Emotional Blunting in Behavioral Variant Frontotemporal Dementia Compared to Alzheimer's Disease

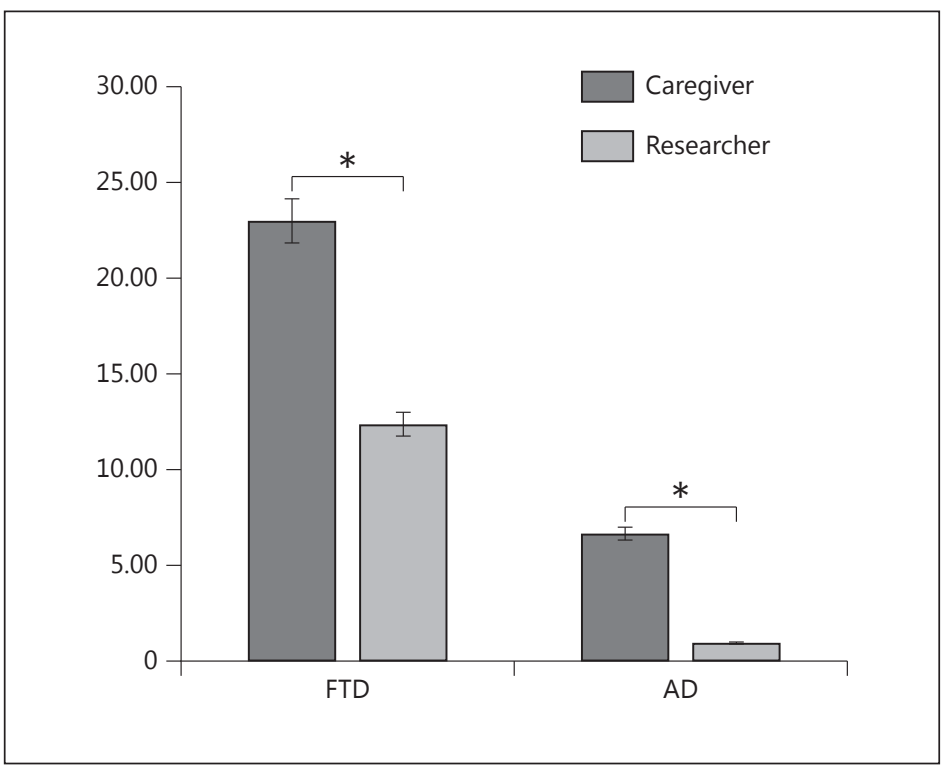

\begin{tabular}{lcrll}
\hline SEB & $\begin{array}{l}\text { bvFTD - } \\
\text { researcher } \\
(\mathrm{n}=13)\end{array}$ & $\begin{array}{l}\text { bvFTD - } \\
\text { caregiver } \\
(\mathrm{n}=13)\end{array}$ & $\begin{array}{l}\text { AD - } \\
\text { researcher } \\
(\mathrm{n}=18)\end{array}$ & $\begin{array}{l}\text { AD - } \\
\text { caregiver } \\
(\mathrm{n}=18)\end{array}$ \\
\hline Total & $12.38(11.5)$ & $23.0(7.9)$ & $0.94(0.9)$ & $6.67(6.0)$ \\
Affect & $3.00(3.21)$ & $6.23(2.7)$ & $0.17(0.5)$ & $2.00(2.2)$ \\
Behavior & $5.46(5.1)$ & $10.08(4.1)$ & $0.39(0.6)$ & $3.17(3.1)$ \\
Thought & $3.92(3.7)$ & $6.77(1.7)$ & $0.28(0.5)$ & $1.50(1.7)$ \\
\hline
\end{tabular}

Values in parentheses are SD. 
Dementia

and Geriatric

Cognitive Disorders

\begin{tabular}{l|l}
\hline Dement Geriatr Cogn Disord 2014;38:79-88 \\
\hline DOI: $10.1159 / 000357838$ & $\begin{array}{l}\text { ○ 2014 S. Karger AG, Basel } \\
\text { www.karger.com/dem }\end{array}$ \\
\hline
\end{tabular}

Joshi et al.: Evaluation of Emotional Blunting in Behavioral Variant Frontotemporal Dementia Compared to Alzheimer's Disease

\section{Discussion}

In this study, dementia caregivers reported more severe changes in emotional blunting among patients with bvFTD compared to those with AD. Both the bvFTD group and the AD group had similar SEB ratings before the onset of dementia, and significantly higher SEB ratings after the onset of dementia; however, the extent of change was considerably greater among those with bvFTD. In a logistic regression model, the degree of change in emotional blunting was an excellent diagnostic marker that correctly discriminated bvFTD patients from AD patients with $90 \%$ accuracy. A cutoff change score of $\geq 15$ on the SEB (caregiver rated before and after dementia onset) provided a sensitivity of $92 \%$ and a specificity of $80 \%$ in distinguishing FTD and AD groups. The current results support prior findings that emotional blunting is a key syndromic feature in bvFTD [10], and that caregiver report of this feature can accurately differentiate individuals with bvFTD versus early-onset AD [1].

In the current study, caregivers from both dementia groups reported higher SEB scores compared to the researcher. In line with recent research, bvFTD caregivers exhibited more severe burden than the AD caregivers did [25-27], which was positively associated with patient emotional blunting and apathy (NPI) [28]. The greater degree of caregiver burden in bvFTD appears to be related to neuropsychiatric symptoms as well as deficits in adherence to social norms and emotional reciprocity $[29,30]$. Despite the potential for bvFTD caregiver distress to color the ratings from caregivers, the degree of caregiver burden did not predict emotional blunting scores in the sample, indicating that the caregiver SEB difference ratings were not primarily due to caregiver distress.

There was a significant positive correlation between caregiver SEB difference score (subtracting before dementia onset from after dementia onset) and the presence of right and left frontal hypometabolism on PET imaging. Our previous work had noted that right frontal hypoperfusion on SPECT imaging in patients with bvFTD patients was associated with apathy and loss of insight [31]. Other investigators have found that bvFTD patients with greater right-sided frontotemporal hypoperfusion on SPECT exhibited greater emotional blunting on the SEB than those with bilateral or left-sided prominent hypoperfusion [9]. This study supports the association of both right and left frontal metabolism and emotional blunting in bvFTD patients.

There was also a significant negative correlation between caregiver SEB difference score and the presence of right and left parietal hypometabolism. A potential explanation for the association between lower emotional blunting and parietal hypometabolism is dysfunction in frontoparietal networks. Recent studies suggest that frontal and parietal regions work together in networks that control appraisal and responsiveness to social emotions [32]. It is possible that decreased frontal functions in the presence of maintained parietal functions result in a failure in frontal-parietal control processes for socially based cognitive, affective and behavioral expression.

The current findings suggest that caregivers are ready to provide an assessment of patients' emotional blunting. Despite the fact that caregiver SEB scores are positively correlated with the caregiver burden scale, their distress does not impair their ability to objectively report socioemotional symptoms in a family member. Pathologic emotional expression is most likely to be detected by someone close to the patient who observes them over time and across a variety of settings, whereas clinicians typically assess patients in a relatively brief time frame and in situations where patients are likely to put their best foot forward. Therefore, caregivers are at a greater advantage in providing an assessment of the patient's behavior.

The study has several potential limitations. First, the sample size is relatively small. Nevertheless, the repeated-measures design and other analyses revealed significant group differences in the SEB ratings. The SEB difference cutoff score $(\geq 15)$ needs further validation 
Joshi et al.: Evaluation of Emotional Blunting in Behavioral Variant Frontotemporal

Dementia Compared to Alzheimer's Disease

with a larger sample size in a future study. Second, the caregivers were primarily spouses. The study did not have professional caregivers, children, siblings or others as primary caregiver; thus, the generalizability of these results may be limited. However, the spouses were the most likely to know the patients well and to most effectively rate their degree of emotional blunting.

The study affirms emotional blunting as a hallmark feature of bvFTD. The structured assessment of this symptom can help aid in the differential diagnosis of bvFTD. Specifically, caregiver-based ratings of emotional blunting are essential in the early detection of bvFTD [33]. Clinicians will improve their accuracy in discriminating neurodegenerative diseases by obtaining caregiver SEB ratings before and after the onset of dementia, similar to other caregiver-based measures [34, 35]. In this study, SEB scores from both clinician and caregiver ratings can be used for clinical comparison (table 3). The caregiver report of SEB differences quantifies the level of impairment in emotional reactivity and expression among bvFTD patients and could be used for the management and longitudinal follow-up of disease progression.

In conclusion, the patients' emotional blunting reported by a caregiver can help clinicians to differentiate between bvFTD and other dementias during early stages of the disorder. Future work can profitably focus on additional areas of discrepancy between caregiver and clinician rating and evaluate the diagnostic utility of the caregiver perspective.

\section{Acknowledgements}

This study was supported by NIA Grant No. R01AG034499-04 and the VA GRECC Advanced Fellowship in Geriatrics Award (J.B.). We acknowledge Dr. Natalie Wolcott for neuropsychological evaluations.

\section{References}

1 Mendez MF, McMurtray A, Licht E, Shapira JS, Saul RE, Miller BL: The scale for emotional blunting in patients with frontotemporal dementia. Neurocase 2006;12:242-246.

2 Rascovsky K, Hodges JR, Knopman D, Mendez MF, Kramer JH, Neuhaus J, van Swieten JC, Seelaar H, Dopper EG, Onyike CU, Hillis AE, Josephs KA, Boeve BF, Kertesz A, Seeley WW, Rankin KP, Johnson JK, Gorno-Tempini ML, Rosen H, Prioleau-Latham CE, Lee A, Kipps CM, Lillo P, Piguet O, Rohrer JD, Rossor MN, Warren JD, Fox NC, Galasko D, Salmon DP, Black SE, Mesulam M, Weintraub S, Dickerson BC, Diehl-Schmid J, Pasquier F, Deramecourt V, Lebert F, Pijnenburg Y, Chow TW, Manes F, Grafman J, Cappa SF, Freedman M, Grossman M, Miller BL: Sensitivity of revised diagnostic criteria for the behavioural variant of frontotemporal dementia. Brain 2011; 134:2456-2477.

3 Neary D, Snowden JS, Gustafson L, Passant U, Stuss D, Black S, Freedman M, Kertesz A, Robert PH, Albert M, Boone K, Miller BL, Cummings J, Benson DF: Frontotemporal lobar degeneration: a consensus on clinical diagnostic criteria. Neurology 1998;51:1546-1554.

4 McMurtray AM, Ringman J, Chao SZ, Licht E, Saul RE, Mendez MF: Family history of dementia in early-onset versus very late-onset Alzheimer's disease. Int J Geriatr Psychiatry 2006;21:597-598.

5 Paradiso S, Ostedgaard K, Vaidya J, Ponto LB, Robinson R: Emotional blunting following left basal ganglia stroke: the role of depression and fronto-limbic functional alterations. Psychiatry Res 2013;211:148-159.

- 6 Pietersen CY, Bosker FJ, Doorduin J, Jongsma ME, Postema F, Haas JV, Johnson MP, Koch T, Vladusich T, den Boer JA: An animal model of emotional blunting in schizophrenia. PLoS One 2007;2:e1360.

- 7 Kumfor F, Piguet O: Disturbance of emotion processing in frontotemporal dementia: a synthesis of cognitive and neuroimaging findings. Neuropsychol Rev 2012;22:280-297.

8 Mendez MF, Joshi A, Tassniyom K, Teng E, Shapira JS: Clinicopathologic differences among patients with behavioral variant frontotemporal dementia. Neurology 2013;80:561-568.

9 Boone KB, Miller BL, Swartz R, Lu P, Lee A: Relationship between positive and negative symptoms and neuropsychological scores in frontotemporal dementia and Alzheimer's disease. J Int Neuropsychol Soc 2003;9: 698-709.

10 Mathias JL, Morphett K: Neurobehavioral differences between Alzheimer's disease and frontotemporal dementia: a meta-analysis. J Clin Exp Neuropsychol 2010;32:682-698. 
Joshi et al.: Evaluation of Emotional Blunting in Behavioral Variant Frontotemporal

Dementia Compared to Alzheimer's Disease

11 Scherer KR, Clark-Polner E, Mortillaro M: In the eye of the beholder? Universality and cultural specificity in the expression and perception of emotion. Int J Psychol 2011;46:401-435.

12 Sollberger M, Neuhaus J, Ketelle R, Stanley CM, Beckman V, Growdon M, Jang J, Miller BL, Rankin KP: Interpersonal traits change as a function of disease type and severity in degenerative brain diseases. J Neurol Neurosurg Psychiatry 2011;82:732-739.

-13 Naglie G, Hogan DB, Krahn M, Black SE, Beattie BL, Patterson C, Macknight C, Freedman M, Borrie M, Byszewski A, Bergman H, Streiner D, Irvine J, Ritvo P, Comrie J, Kowgier M, Tomlinson G: Predictors of family caregiver ratings of patient quality of life in Alzheimer disease: cross-sectional results from the Canadian Alzheimer's Disease Quality of Life Study. Am J Geriatr Psychiatry 2011;19:891-901.

14 Gifford KA, Liu D, Lu Z, Tripodis Y, Cantwell NG, Palmisano J, Kowall N, Jefferson AL: The source of cognitive complaints predicts diagnostic conversion differentially among nondemented older adults. Alzheimers Dement 2013, Epub ahead of print.

15 Pijnenburg YA, Mulder JL, van Swieten JC, Uitdehaag BM, Stevens M, Scheltens P, Jonker C: Diagnostic accuracy of consensus diagnostic criteria for frontotemporal dementia in a memory clinic population. Dement Geriatr Cogn Disord 2008;25:157-164.

16 Hooten WM, Lyketsos CG: Differentiating Alzheimer's disease and frontotemporal dementia: receiver operator characteristic curve analysis of four rating scales. Dement Geriatr Cogn Disord 1998;9:164-174.

-17 Fazekas F, Chawluk JB, Alavi A, Hurtig HI, Zimmerman RA: MR signal abnormalities at 1.5 T in Alzheimer's dementia and normal aging. AJR Am J Roentgenol 1987;149:351-356.

18 McKhann GM, Knopman DS, Chertkow H, Hyman BT, Jack CR Jr, Kawas CH, Klunk WE, Koroshetz WJ, Manly JJ, Mayeux R, Mohs RC, Morris JC, Rossor MN, Scheltens P, Carrillo MC, Thies B, Weintraub S, Phelps CH: The diagnosis of dementia due to Alzheimer's disease: recommendations from the National Institute on AgingAlzheimer's Association workgroups on diagnostic guidelines for Alzheimer's disease. Alzheimers Dement 2011;7:263-269.

19 Abrams R, Taylor MA: A rating scale for emotional blunting. Am J Psychiatry 1978;135:226-229.

20 Berenbaum SA, Abrams R, Rosenberg S, Taylor MA: The nature of emotional blunting: a factor-analytic study. Psychiatry Res 1987;20:57-67.

21 Folstein M, Folstein S: Invited reply to 'The death knoll for the MMSE: has it outlived its purpose?' J Geriatr Psychiatry Neurol 2010;23:158-159.

22 Cummings JL, Mega M, Gray K, Rosenberg-Thompson S, Carusi DA, Gornbein J: The neuropsychiatric inventory: comprehensive assessment of psychopathology in dementia. Neurology 1994;44:2308-2314.

-23 Zarit SH, Reever KE, Bach-Peterson J: Relatives of the impaired elderly: correlates of feelings of burden. Gerontologist 1980;20:649-655.

24 Reitan RM, Wolfson D: The Halstead-Reitan Neuropsychological Test Battery: Therapy and Clinical Interpretation. Tucson, Neuropsychological Press, 1985.

-25 Mioshi E, Foxe D, Leslie F, Savage S, Hsieh S, Miller L, Hodges JR, Piguet O: The impact of dementia severity on caregiver burden in frontotemporal dementia and Alzheimer disease. Alzheimer Dis Assoc Disord 2013;27: 68-73.

26 Mioshi E, Bristow M, Cook R, Hodges JR: Factors underlying caregiver stress in frontotemporal dementia and Alzheimer's disease. Dement Geriatr Cogn Disord 2009;27:76-81.

-27 Riedijk SR, De Vugt ME, Duivenvoorden HJ, Niermeijer MF, Van Swieten JC, Verhey FR, Tibben A: Caregiver burden, health-related quality of life and coping in dementia caregivers: a comparison of frontotemporal dementia and Alzheimer's disease. Dement Geriatr Cogn Disord 2006;22:405-412.

28 George M: Association between apathy and the caregiver burden in amnestic mild cognitive impairment and Alzheimer's disease. J Neurol Neurosurg Psychiatry 2013;84:e1.

29 Hsieh S, Irish M, Daveson N, Hodges JR, Piguet 0: When one loses empathy: its effect on carers of patients with dementia. J Geriatr Psychiatry Neurol 2013, Epub ahead of print.

-30 Sturm VE, McCarthy ME, Yun I, Madan A, Yuan JW, Holley SR, Ascher EA, Boxer AL, Miller BL, Levenson RW: Mutual gaze in Alzheimer's disease, frontotemporal and semantic dementia couples. Soc Cogn Affect Neurosci 2011;6:359-367.

-31 McMurtray AM, Chen AK, Shapira JS, Chow TW, Mishkin F, Miller BL, Mendez MF: Variations in regional SPECT hypoperfusion and clinical features in frontotemporal dementia. Neurology 2006;66:517-522.

-32 Wessing I, Rehbein MA, Postert C, Furniss T, Junghofer M: The neural basis of cognitive change: reappraisal of emotional faces modulates neural source activity in a frontoparietal attention network. Neuroimage 2013;81: $15-25$.

33 Jicha GA: Medical management of frontotemporal dementias: rhe importance of the caregiver in symptom assessment and guidance of treatment strategies. J Mol Neurosci 2011;45:713-723.

-34 Malloy P, Grace J: A review of rating scales for measuring behavior change due to frontal systems damage. Cogn Behav Neurol 2005;18:18-27.

35 Grace J, Malloy P: Frontal Systems Behavior Scale (FrSBe): Professional Manual. Lutz, Psychological Assessment Resources, Inc., 2001. 